\title{
PROBLEMÁTICA DEL BRONCE FINAL EN LA MESETA*
}

\section{DEBATING THE LATE BRONZE AGE IN THE SPANISH CENTRAL PLATEAU}

\author{
por \\ $\mathrm{M}^{\mathrm{a}}$ CONCEPCIÓN BLASCO BOSQUED Y \\ $\mathrm{M}^{\mathrm{a}}$ ROSARIO LuCAS PELlicer
}

RESUMEN Caracterización cultural de Cogotas I, ahondando en los orígenes, problemática de su agotamiento y tránsito al Hierro I.

ABSTRACT Cultural feature of Cogotas I, deepening into its origins, problems of its depletion and transit to Iron Age.

Palabras claves Bronce Final, Cogotas I, Meseta Central.

Key words Latter Bronze Age, Cogotas I, Central Meseta of Spain.

En 1989 el Dr. Pellicer subrayaba que el inicio de Cogotas I podría estar en el mundo campaniforme y puntualizaba: "En tal caso, nos encontramos... con el absurdo de pasarse directamente del calcolítico final o del campaniforme al bronce tardío o final de Cogotas I. La Meseta, necesariamente, por la amplitud cronológica de Cogotas I debe de participar, como sucede en otros círculos hispanos, de un bronce antiguo, medio y reciente, para terminar dentro de un hierro antiguo" (1992:14).

En efecto, reiteradamente se ha insistido en que la génesis y el origen de Cogotas I están vinculados con las tradiciones locales del área nuclear en la que se integran los valles del Tajo y Duero, hipótesis que hoy empieza a estar plenamente confirmada, sin embargo dicha tradición, aunque puede arrancar desde época muy remota, tiene especial continuidad desde el Bronce Antiguo de ambas cuencas, horizonte que se conoce a través de lugares de hábitats situados en las terrazas bajas de los ríos. Estos establecimientos se caracterizan por sus agrupaciones de "silos" o fosas excavadas en el subsuelo que conforman los espacios domésticos de alzados perecederos y desconocidos, entre los que se distribuyen algunos enterramientos de inhumación en fosa, con ciertas similitudes con los comúnmente denominados argáricos; también en el equipo material (industria lítica, metalúrgica y cerámica) se observan similitudes técnicas y morfológicas,

\footnotetext{
* Este trabajo ha sido realizado dentro del proyecto BHA 2001-0715. Subvencionado por el MCYT.
} 
aun reconociendo la diferencia entre las dos áreas culturales. Entre los yacimientos que pueden adscribirse a este horizonte hay que mencionar los enterramientos de Villalmanzo o los hábitats con enterramientos de Loma del Lomo y Tejar del Sastre/La Perla.

Tras el Bronce Antiguo, casi sin solución de continuidad, se ha identificado en ambas Mesetas un segundo horizonte denominado Protocogotas cuyos asentamientos, similares a sus precedentes, rara vez coinciden con los del Bronce Antiguo, aunque frecuentemente se localizan en puntos en donde más tarde se instalarán las gentes del Bronce Final -Cogotas I- dando lugar a estratigrafías horizontales en aquellas zonas donde se suceden estructuras y silos correspondientes a distintos momentos (Fig. 1.1). La reiterada confirmación de que algunos "silos" pertenecientes a Cogotas I se perforaron coincidiendo con los precedentes se ha interpretado en el sentido de abandono temporal, más o menos largo, y de reocupaciones discontinuas; a su vez, el testimonio de dos etapas distintas en un mismo lugar con características similares, ha propiciado cierta confusión cultural hasta el punto de incluir dentro de Cogotas I, sin matices temporales, todos los conjuntos en los que aparecían cerámicas decoradas con técnicas de incrustación, postulado que hoy queda superado ante la confirmación, tanto en yacimientos de la cuenca del Duero como en la del Tajo, de una primera fase Protocogotas fechada en los siglos XV y XVI (Blasco et alii 1995) y por tanto dentro del Bronce Medio y una segunda, plenamente Cogotas I, a partir del s. XIV y hasta el VIII a. C. La primera de estas fases, también conocida como Cogeces o Protocogotas, auténtica bisagra entre el Bronce Antiguo y el Reciente (inicios de Cogotas I), se presenta como una continuidad sin ruptura violenta. Se caracteriza por un tipo de hábitat y estructuras domésticas similares a las del Bronce Antiguo y por contadas inhumaciones individuales en fosa dentro del poblado. También persiste la industria lítica de carácter laminar y el laboreo del metal dentro del hábitat, pero se observan como novedades o indicios del cambio cultural, la ausencia de pithoi, la progresiva adopción de la metalurgia del bronce binario, cambios formales en los recipientes (carenas altas) y el gusto por la decoración de incrustación (impresiones e incisiones) desarrollando temas sencillos (líneas corridas, zig-zags y triángulos...) con escasa o nula presencia del boquique y la excisión.

La base económica de estas poblaciones, eminentemente campesina, hunde sus raíces en tradiciones anteriores donde la itinerancia cíclica es una estrategia de optimización de los recursos agropecuarios: clareo del bosque, cereales complementados con leguminosas (López, coord. 1997) pastoreo de ganado vacuno y lanar y cuidado del cerdo, favoreciendo los desplazamientos la obtención de materias primas.

En cualquier caso, aun dentro de esta economía de apariencia autárquica, a lo largo del segundo milenio a. C. las relaciones con la periferia peninsular son especialmente evidentes por la presencia de estas cerámicas meseteñas en yacimientos tan singulares como Setefilla (Sevilla), El Berrueco en Medina Sidonia (Cádiz), Peñalosa (Jaén ), Campello (Alicante) y, en el tránsito a Cogotas I, hallazgos como los de Cabezo Redondo de Villena (Alicante) o Llanete de los Moros en Montoro (Córdoba) entre otros y que, a falta de otra explicación, han de valorarse como ampliación de las redes regionales y de los contactos (Abarquero 1999).

\section{EL HORIZONTE COGOTAS I}

Hoy se identifica como una etapa relativamente bien diferenciada tanto de la fase de formación a la que se ha hecho referencia, como del Hierro I, y su momento de plenitud es sincrónico al Bronce Tardío-Final. Los hábitats siguen presentando agrupaciones de fosas similares a sus precedentes, aunque parece detectarse una cierta disminución en la capacidad de estos hoyos. Corresponden a tres modelos de asentamiento:

1) En terrazas bajas junto a la confluencia de un río principal con un curso secundario coincidiendo muchas veces con asentamientos previos, ratificando así la movilidad cíclica de amplia tradición que sólo se agotará con el propio declive de Cogotas I. Este es el modelo más generalizado y sobre el que más ha insistido la bibliografía (Fig. 1.1 y 2). 
2) En alto, sobre las cumbres de los cerros. Este modelo, menos conocido, está bien representado en el valle del Henares en cerros testigos como Ecce Homo y Muela de Alarilla, o en otras zonas como el cerro del Bu en Toledo (Fig. 1.4).

El alcance territorial de esta modalidad de asentamiento, no fortificado y con estructuras en hoyos y alzados efímeros, ratifica la estratigrafía horizontal en aparente sincronía con las ocupaciones en fondos de valle y demuestra una clara tendencia expansiva hacia los rebordes montañosos, buscando estratégicamente una posición dominante relacionada con el control de pasos naturales en el cambio de vertientes, cabeceras de aguas, vados o amplia visibilidad de los valles (en estas mismas cumbres se emplazarán posteriormente torres vigías y castillos).

Los materiales de estos asentamientos en alto son de amplia cronología lo que asegura una presencia humana dilatada en el tiempo, aunque no estemos en condiciones de pronunciarnos sobre si las estratigrafías horizontales han de interpretarse como una ocupación continua, desplazando las viviendas dentro una misma área o discontinua con itinerancia/estacionalidad dentro del territorio, al igual que se atestigua en los yacimientos en terrazas bajas, modelo este último, con el que, en términos generales, se identifica la base social y económica de estas poblaciones agropecuarias de bajo rendimiento no plenamente sendentarizadas, pero bien adaptadas al territorio, ganando tierras a costa del bosque y matorral y, por tanto, desde el punto de vista de la investigación, con serias dificultades para estimar la densidad demográfica de conjunto, el tamaño de las agrupaciones secuenciales en los hábitats (la extensión lineal puede superar los $500 \mathrm{~m}$.) e incluso el ritmo de variabilidad temporal. En cualquier caso, y hasta donde sabemos, el patrón de asentamiento no está determinado por la directa interrelación entre yacimientos en llano en torno a un poblado en alto, sino por la coyuntura de los accidentes geográficos y los recursos hídricos, privando la extensión frente a la concentración, sin ninguna presión por la explotación de la tierra o la obtención de materias primas, entre ellas las susceptibles de obtener cobre, estaño y sal (sobre todo para el ganado).

3) Un tercer tipo de asentamiento se localiza en laderas de abruptos escarpes, modalidad que ha de entenderse como extensión esporádica de los dos modelos principales hacia ambientes que se aproximan o enclavan en la Sierra, ocupando pendientes con importantes desniveles, bien al socaire de abrigos, como Los Aljibes en Manzanares el Real o al aire libre, caso de Cancho Gordo en La Cabrera (Madrid) o Yecla de Silos en Burgos, estos ejemplos son sólo parte de una nómina más larga de yacimientos que responden a asentamientos muy puntuales, de corta duración, en sitios de difícil acceso (Fig. 1.3).

Desde el punto de vista social, la unidad arqueológica de Cogotas I en ambas Mesetas sólo puede explicarse por grupos de organización parentelar, insertos en amplias redes regionales con fluidez de contactos, salvando la apariencia engañosa de las barreras naturales (Abarquero 1999).

Respecto a las manifestaciones funerarias (Esparza 1990 ; González Tablas y Fano 1994) o de prácticas que atañen a la esfera cognitiva, Cogotas I parece prolongar, en contextos domésticos, las mismas evidencias presentes ya en la etapa Protocogotas (Blasco et alii 1991: 63-64), aunque en proporciones progresivamente inferiores, y la presencia esporádica, en ambas mesetas, de restos humanos entre rellenos de desecho (Esparza 1990). No se han evidenciado, sin embargo, ofrendas o depósitos de animales completos (Blasco et alii 1984-85) aunque sí suelen aparecer en el interior de las fosas restos parciales, sobre todo cornamentas y vasos invertidos, prácticas todas ellas que deben remitir a la propiedad/protección simbólica del espacio en relación con el ancestral abandono temporal del hábitat (Cunliffe 1992).

En cuanto a la explotación de la tierra, los escasos diagramas botánicos (López, coord. 1997: 150 y ss), representativos del hábitat en alto (Cerro del Ecce Homo) y en ribera (Caserío de Perales) documentan un paisaje altamente antropizado, con deforestación progresiva en favor del cultivo de regadío de variadas leguminosas (entre ellas favaceae) en ambientes riparios y de cultivos no muy extensos de cereales (trigo y cebada desnuda) en áreas de secano más alejadas de los yacimientos, con alta representación de las chicorioideas y especies nitrófilas que apuntan a la cercanía de campos de cultivo y pastizales. Además 
del aprovechamiento de recursos vegetales silvestres, como la bellota, existe la posibilidad del cultivo arbóreo de acebuches y nogales.

En complementariedad, la cabaña ganadera, a falta de un estudio faunístico de conjunto, está dominada por el ganado ovicaprino (más ovejas que cabras) seguida de bóvidos, relativamente abundantes con posible uso en la tracción (Blasco y Barrio 1986); los cerdos están representados por animales relativamente jóvenes y, siempre en minoría, aparecen caballos y perros. La caza es relativamente abundante (ciervos, conejos, jabalíes y algún ejemplar de lobo y oso) y más frecuente que durante las etapas del hierro.

En cuanto a la cultura material, dientes de hoz, molinos barquiformes de granito, molederas/machacadores, así como vasos coladores o queseras forman parte del equipo de explotación vegetal y transformación de alimento, mientras las pesas de telar o las improntas atestiguan la producción textil y el trabajo de fibras $\mathrm{y}$ trenzados vegetales.

Las cerámicas más toscas son continuistas y los recipientes cuidados, porcentualmente abundantes, son los que ofrecen morfología y decoración novedosas que caracterizan el estilo de Cogotas I. Técnicamente también existen cambios, las superficies son más cuidadas que las de Protocogotas, espatuladas o bruñidas, con sensible reducción del grosor de las paredes y además se incorporan usos funcionales o servicios nuevos a juzgar por el aumento de tamaño de una serie de recipientes, que agigantan la forma de cazuela o fuentes hondas.

Si la morfología vascular de la etapa Protocogotas (Fig. 2.1) deriva de los perfiles más característicos de los vasos lisos del Bronce Antiguo peninsular, incluido el desarrollo de perfiles con marcada línea de carena, a mayor o menor altura, diferenciando, en la parte inferior, un cuerpo de paredes convexas (las típicas fuentes o cazuelas), con el avance de Cogotas I se impone, en todos los ambientes, una silueta marcadamente sinuosa al contraponer a la parte alta del cuerpo, un "tronco de cono" de paredes cóncavas de base extremadamente reducida en proporción con la capacidad y las medidas (Fig. 2.2 y 3); además el repertorio cerámico se enriquece con nuevas formas, como las jarras con asa, de boca circular o lobulada y los soportes en clepsidra (para estabilizar recipientes) (Fig. 2.5 a 7), piezas estas últimas minoritarias en el volumen de cerámicas, pero importantes como indicadores de contactos extrarregionales y del no estancamiento material de Cogotas I. Por otra parte, estas novedades ajenas al bagaje tradicional, están acompañadas con cambios significativos en técnicas, motivos y sintaxis ornamentales, con resultados que podríamos resumir en dos palabras: creciente barroquismo y heterogeneidad. Así, aun continuando la tradición de decorar bordes y situar exteriormente la decoración en la parte alta del vaso, se advierte el avance progresivo de la ornamentación siguiendo la arquitectura del recipiente y sobre todo novedades tales como el dominio y amplitud de profundas excisiones y anchas acanaladuras de fondo muy irregular ${ }^{1}$, la impresión de cuerda, unida a las técnicas tradicionales de boquique, líneas cosidas, puntillado... sea como motivos complementarios de cenefas corridas, discontinuas o metopadas, recrea grandes bandas ornamentales en las que proliferan incrustaciones postccocción de pastas blancas/ocres o rojas; se mantiene la organización de los motivos en frisos aunque ahora con un dinámico y novedoso repertorio: "doble hacha" (medias lunas contrapuestas) (Fig. 2.3), doble o simple círculo trazado con diferentes instrumentos, además de exageradas estrellas o triángulos rayados, arcos concéntricos, guirnaldas, grandes círculos a modo de bullones en correspondencia con las llamadas "jibosidades" (Fig. 2.4 y 5) (Delibes et alii 1990 ), etc.

Estos cambios formales y ornamentales no parecen casuales y autónomos sino fruto de la reinterpretación de una moda europea que toma cariz de variable cultural dentro de Cogotas I, al responder a unos modelos

1. Queremos llamar al atención sobre la técnica empleada en excisiones y acanaladuras. Se trata de anchas y profundas bandas o espacios cuya superficie interna, lejos de la regularidad y tamaño de las excisas tipo Redal o de las acanaladas del NE, presenta notables altibajos y gran tosquedad: la sustracción se ha realizado de forma discontinua o a golpes, seguramente cuando la cerámica estaba muy seca y no permitía una homogeneidad. Las diferencias, incluso con excisiones más toscas como son las de tipo Roquizal del Rullo, hacen pensar en imitaciones de algo que se ha visto, sin dominar el procedimiento, y a no ser que toda esta ornamentación se ocultara con otros materiales (improbable, pues los testimonios de color incrustado no se pueden generalizar) es obvio que importaba más el efecto visual de claroscuro y abigarramiento que la perfección instrumental. 
generalizados y a unos patrones estéticos identificadores y reconocibles. Un buen parangón para las modalidades ornamentales se halla en la vajilla de los ambientes de CU de Europa Central, especialmente en zonas alpinas y en el entorno suizo de Le Bourget así como en la decoración de la metalistería destinada a adornos personales. Ante estos paralelos forzosamente hemos de mirar a Europa, no en el sentido de revindicar viejas teorías, sino con objeto de valorar préstamos e intentar comprender la recreación de aspectos de larga trayectoria y difusión, en un momento en que la península está abierta a circuitos mediterráneos y atlánticos y a los contactos continentales.

Bullones y perfiles cóncavos arrancan tímidamente en el Ha A y despegan en el $\mathrm{Ha} \mathrm{B}$ de las regiones austro-bávaras y renano-suizas, extendiéndose hacia Francia y los Alpes (Pellicer 1984), alternando o complementando motivos como los reseñados para Cogotas I, con técnicas muy próximas y complejidad de diseños, que en combinaciones ornamentales y técnicas (impresiones, incrustaciones de cuerdas, metal y colorantes como grafito y hematites) de acusado barroquismo alcanzan su máxima expresión durante el tránsito y comienzos del Ha C (Werner 1987). Pero es precisamente en la decoración de los objetos de metal, sobre todo brazaletes o pulseras y fíbulas, extendidos desde el Norte de Europa hasta el Atlántico, tanto en ambientes incineradores (Chertier 1976) como en la prolongación de los túmulos (Brun 1986: lám. 6,66 , passim) donde se reitera el motivo de las medias lunas o arcos contrapuestos en metopas, separadas por líneas trasversales o trazando losanges. El mismo camino han debido recorrer las guirnaldas, los círculos impresos. Estos motivos, además de en ambientes alpinos alcanzan cierto favor técnico en las cerámicas tardías del Grupo Gürdlingen-Ossingen-Singen (SE de la Cuenca de París) (BF III o Ha B3 de Müller Karpe) (Brun 1986: lám. 68) y la plenitud de su difusión en las cerámicas europeas del Hierro Antiguo, aunque los objetos de metal son soporte preferente de esta ornamentación geométrica. Estas analogías entre Cogotas I y las modas ornamentales europeas en su conjunto han de considerarse como un flujo transpirenaico dentro de las corrientes que, procedentes de Europa Central, alcanzan el occidente europeo, no tanto por extensión desde el NE español (ausente entre otros, el motivo de "doble hacha") sino por los Pirineos Occidentales o Centrales, como parece testimoniar la fuerza del estilo cerámico de Cogotas I en el Alto y Medio Ebro (Rodanés 1995; Abarquero 1999:123) con materiales tan señeros como los de Álava y la integración de todas las novedades señaladas en el área nuclear de Cogotas I.

Estas recurrencias hacen pensar, con independencia de pequeñas migraciones, que desde los ambientes renanos o suizos existieron redes interregionales que llegaron a formar una auténtica arteria, enlazando el Centro/Occidente francés con el Atlántico y con el Ebro, circuito que explicaría asimismo la antigüedad alcanzada por la "pintura" al grafito en Álava y Ebro Medio (Werner 1987: 88).

En complemento con lo anterior, el jarro con asa de cinta acodada o en puente vertical halla sus analogías formales, incluida el asa, en el Bronce Valenciano, enlazando con el arraigo y evolución de las botellas sin asas propias del Bronce Tardío del SE, y con una dirección de flujo y reflujo en el aspecto decorativo de algunos ejemplares (Mesado 1999: 12, fig. 76 y 79). Pero la forma no es un trasunto fiel ni estático, admite variantes en la esbeltez del cuerpo, posición del asa y sintaxis decorativa: la del arenero de Valdivia incorpora amplios campos excisos realzando grandes círculos bordeados a su vez por impresión a cuerda (Fig. 2.5), con un efecto todavía más barroco que el ejemplar vallisoletano de San Román de la Hornija (Delibes et alii 1990).

Otras piezas singulares, como los tres soportes en forma de carrete: arenero madrileño de Valdivia (Pérez de Barradas 1936) (Fig. 2.7); Cerro del Padrastro en Santamera, Guadalajara (Valiente 1992: 18 y fig. 3 , 12 y 23) Alto de Yecla en Silos, Burgos (Almagro 1975: 209) comparten también el estilo propio de Cogotas I y son recurrentes en la decoración desarrollada: llamativa línea quebrada en un campo exciso, que anula la típica decoración de línea cosida, característica de Cogotas I.

Esta sencilla forma de soporte no cuenta en la región con tradiciones calcolíticas o del Bronce que presupongan antecedentes locales; bien al contrario, el modelo ha debido llegar con la extensión de este tipo de pieza durante el Bronce Final peninsular avanzado (bronce tartésico y bronce final del Sudeste) y etapa 
orientalizante. En nuestro caso no sabemos si la adopción se debe únicamente a la necesidad de estabilizar los recipientes de precaria base o a la introducción de ceremonias y servicios de mesa comunes a distintas áreas. La forma presente en Cogotas I se corresponde con el grupo $3 \mathrm{~b}$, sin anillo en el estrangulamiento (tartésico pleno), de la clasificación de P. Gasull (1982) y la incorporación al bagaje cerámico de Cogotas I hemos de aceptarla como un préstamo más de los influjos mediterráneos en la Meseta, en un momento de pleno cambio cultural, posiblemente en el tránsito o inicios del Hierro I, ya sea desde el Mediodía o desde el Levante ${ }^{2}$.

Valoradas las novedades cerámicas, hay que insistir que la tradición local, sin ninguna ruptura, pesa tanto en la producción de recipientes comunes como en la persistencia de la incrustación y de algunos temas decorativos como triángulos, zig-zags, punteados, etc., aunque en general se asocian a otros motivos para crear composiciones más abigarradas y dar cabida a la combinación de viejas y nuevas técnicas con el complemento del color.

Las industrias lítica y ósea, excesivamente monótonas y prácticas, aportan pocas novedades y en el caso de la lítica cabe destacar el definitivo abandono de la técnica laminar y la exclusiva producción de los recurrentes dientes de hoz en forma de media luna. Sin embargo, la metalurgia ayuda a comprender la personalidad de Cogotas I frente a etapas previas: no se atestiguan indicios del procesado del mineral en los hábitats, pero sí menudea el transporte de algún lingotillo, como el raro ejemplar de plomo en forma de "media hacha plana" fundido en una sola valva, localizado en la Fábrica de Ladrillos en el bajo Manzanares o el lingotillo del enterramiento de San Román de la Hornija (Fernández Manzano 1986: 152); además la analítica ratifica la continuidad de excelentes bronces binarios y también ternarios (Blasco y Rovira 1992/93) con la sospecha de hornos más avanzados. En cuanto a los productos acabados siguen estando presentes, cada vez en mayor número, varillas y punzones biapuntados en aleaciones binarias, acompañados de la novedad y extensión de elementos de función más imprecisa, como las anillas abiertas, con analogías en el depósito de Vènat, y sobre todo de novedosos elementos de adorno personal (Fig. 3).

En efecto, además de las conocidas fíbulas de codo tipo Ría de Huelva de San Román de la Hornija (Delibes 1978) (fig. 3. 9), El Berrueco (Fig. 3. 11) y Silos (Fig. 3. 10) (Fernández Manzano 1986) y de la de "ad occhio" del Caserío de Perales (Blasco 1987) (Fig. 3. 12) de claro influjo mediterráneo o de las valoraciones más recientes, contamos con versiones locales de alfileres, como el atribuido al Berrueco (Fig. 3.7), el de cabeza engrosada y aspecto piriforme procedente del Caserío de Perales (Getafe, Madrid) (Fig. 3.6) y la pareja de cabeza gallonada procedente de El Tomillar (Fig. 3.4 y 5), que se unen a la amplitud y variedad de los raros adornos continentales que llegan hasta la Meseta (Delibes 1999-2000) y entre los que hay que incluir el pesado brazalete de bronce con buen porcentaje de estaño procedente de la Muela de Alarilla (Méndez 1994) fragmentado en dos, con recargada decoración geométrica a buril (Fig. 3. 1) posiblemente vinculado a la dispersión de ornamentos que por vía atlántica penetran en la Meseta (Fernández Manzano 1986: passim). Su sección triangular es propia de los primeros momentos del B.F. I (entre otros ejemplos, depósito de Clans, Provenza: Lagrand 1976:454) y en un momento más antiguo, Bronce Medio, sitúa Eluére (1982: fig. 27) el collar áureo de Velluire (Massigny, Vendée), el paralelo más próximo en el diseño geométrico. Por afinidades tecnológicas y estéticas se asocian también a Cogotas I, algunos brazaletes áureos como el de La Torrecilla (Getafe) (Priego y Quero 1978) englobado dentro de la joyería Villena/Estremoz (Armbruster 1993) explicados como testimonios de prácticas rituales o votivas (Delibes, Rodríguez y Santonja 1991).

2. Del yacimiento de Puente Largo, junto a Aranjuez (Madrid), procede el fragmento de otro soporte, en este caso con anillo realzado y no decorado. Su asociación a materiales de ascendencia oriental apunta al Bajo Guadalquivir y Huelva en un momento orientalizante no anterior al s. VII a. C. ( Muñoz y Ortega 1997), si bien soportes “importados" aparecen asociados a las cerámicas micénicas del Llanete de los Moros (Martín de la Cruz y Perlines 1993).

3. Agradecemos al Museo Provincial de Guadalajara y, en especial al Dr. Enrique de Álvaro, Director del mismo hasta comienzos de año de este Museo y a $D^{a} M^{a}$ Luz Crespo, por las facilidades prestadas para su estudio y análisis. 
Cronológicamente toda una serie de hallazgos metálicos bien documentados en la Meseta Norte son coetáneos del desarrollo de Cogotas I, aunque desgraciadamente al formar parte de depósitos o ser hallazgos aislados, impide una relación neta con estos ambientes (Fernández Manzano 1986). El hecho de que este tipo de materiales (hachas de talón y anillas, puntas de lanza y algún otro instrumento) estén presentes en la Meseta Sur, avala el conocimiento de esta metalistería atlántica entre las gentes de Cogotas I más meridionales; ejemplo de ello son las hachas de talón de una o dos anillas y las espadas pistiliformes de posible amortización ritual, localizadas en Sigüenza (Guadalajara), comparables a las de Alhama de Aragón (Zaragoza) o Carboneras en Cuenca. Además a esta dirección atlántica apunta también el conocimiento y práctica de la metalurgia ternaria (Blasco y Lucas 2001).

\section{PROBLEMÁTICA DEL AGOTAMIENTO DE COGOTAS I: EL TRÁNSITO AL HIERRO}

Desgraciadamente y como señaló el Profesor Pellicer en su día (1992), no contamos ni con cronologías bien contrastadas ni con estratigrafías verticales que guíen el devenir temporal y evolutivo de Cogotas I, pero cuanto se conoce por la bibliografía más reciente o por las últimas excavaciones se evidencian, de una manera generalizada, las siguientes conclusiones:

1) La dinámica cultural de las cuencas del Duero y Tajo, bastante homogénea a lo largo de Cogotas I, sigue procesos regionales divergentes y diacrónicos a partir de la crisis que desemboca en el agotamiento de este Horizonte.

2) El área del Duero y más concretamente lo que más tarde será la región vaccea, cristaliza precozmente entre los s. IX y VIII en poblados estables con un modelo propio de asentamiento permanente que caracteriza la denominada cultura de Soto I singularizada por su arquitectura de madera y barro con estructuras de envergadura de planta circular y cierta preocupación defensiva (Delibes et alii 1995) .

3) La periferia occidental, tanto del Duero como del Tajo, matizada por la precocidad de los contactos meridionales a tenor de los hallazgos aislados (toréutica, estelas...) se encadenará al hinterland tartésico sembrando el fermento de lo que será más tarde el círculo vettón (Pereira 1994; Romero y Ramírez 1996).

4) En el Tajo y concretamente en la cuenca alta, ya en el siglo VII, asistimos a un desarrollo cultural diferenciado. Se mantiene la arquitectura efímera, pero aumenta el tamaño de las cabañas, de planta irregular, desaparecen los "campos de silos" y se abandona el hábitat en las terrazas bajas de los ríos, bien sea continuando en los cerros testigos o bien buscando los emplazamientos en laderas y terrazas altas. Partiendo de estos antecedentes y no sin problemas cronológicos, asistimos a un mosaico cultural en el que subyace, dentro del Hierro I, el arranque de los diferentes círculos culturales de las etnias prerromanas: las cabeceras altas darán origen al mundo celtibérico claramente influenciado por la permeabilidad del Ebro y los ambientes mediterráneos. Aparecen y se multiplican los poblados estables de distribución perimetral en torno a un espacio de circulación y murallas defensivas, con viviendas de planta rectangular y arquitectura de piedra y barro, y las primeras necrópolis meseteñas de incineración.

5) La zona central del Tajo, lo que más tarde será la Carpetania, es, de momento, la más atávica en el hábitat y en la economía, ya que la persistencia de la explotación cíclica no favorece la fijación al territorio ni los cambios sociales hasta entrado el Hierro II, hecho que, en relación con otras áreas, explicaría asimismo la tardía aparición de auténticas necrópolis y de asentamientos estables. 
En síntesis, el agotamiento y fragmentación de Cogotas I responde a ritmos diferentes y hay que admitir su divergencia y diacronía incluso en espacios muy próximos. Sin embargo, coincidiendo con la ruptura de la tradición cultural, en paralelo a cuanto sabemos sobre el Bronce Final avanzado en los distintos círculos de la Península Ibérica y a la progresión de los poblados estables con arquitectura de mayor resistencia, asistimos al agotamiento de Cogotas I, en sincronía al declive de la tradición atlántica en favor de lo mediterráneo.

En cuanto a las cerámicas, se detecta un rápido cambio, que no evita desconcertantes similitudes, pese a que la tradición se convierte en mero residuo dentro de la completa renovación del equipo vascular. En la morfología hay una tendencia progresiva a los pequeños vasos de paredes finas, cuencos troncocónicos, elementos de suspensión en forma de mamelones perforados, bases umbilicadas... En los acabados priman las superficies escobilladas, espatuladas y bruñidas, el engobe rojo y al grafito... y en las técnicas ornamentales ganan terreno, frente a la excisión, boquique, etc., el grafito, la pintura postcocción y muy especialmente las incisiones cada vez más finas, con o sin incrustación de color, a la par que en los patrones y motivos decorativos se abandona el gusto por el diseño curvilíneo y se impone el geometrismo rectilíneo compartimentado, muy próximo al gusto de los círculos mediterráneos (Pellicer 1992-93). Estas novedades técnicas, como hemos apuntado, no son privativas del declive de Cogotas I sino que, en términos generales, afectan al proceso de cambio cultural de la Península Ibérica, aunque con porcentajes diferenciados o preferencias según áreas, lo que hace pensar en una koiné de gustos y de nuevos hábitos en el consumo de alimentos y servicios de mesa al menos en las cerámicas más finas.

Volviendo a los planteamientos de nuestro homenajeado y como colofón sólo resta decir que, salvo en algunos reductos del Tajo Central, no es el horizonte de Cogotas I el que "sin hiatus se prolonga hasta Cogotas II del hierro medio" sino que son las manifestaciones de ruptura o cambio cultural las que, de acuerdo a la interacción de los circuitos económicos y áreas de influencia, desembocarán, a fines del VIo principios del $\mathrm{V}$, en la personalidad e idiosincrasia de las etnias prerromanas.

\section{BIBLIOGRAFÍA}

ABARQUERO, F. J. (1999): "Rasgos de identificación de la cerámica de tipo Cogotas I fuera de la Meseta", II Cong. de Arq. Penins. T. III:113-128, Zamora.

ALMAGRO, M. (1975): "La España de las invasiones célticas", en Historia de España dir. por R. Menéndez Pidal, T. I, vol. II, 3a ed., cap. II. Madrid.

ALMAGRO GORBEA, M. y FERNÁNDEZ GALIANO, D. (1980): Excavaciones en el Cerro del Ecce Homo (Alcalá de Henares, Madrid). Madrid.

ARMBRUSTER, B. (1993): "Instruments rotatifs dans l'orfevrerie de l'Age du Bronze dans la Peninsule Ibèrique. Nouvelles connaissances sur la technique des bracelets du Type Villena /Estremoz", Actas I Cong. de Arqueología Peninsular, Trabalhos de Antropología e Etnología, 33 (1-2): 265-283, Porto. BALDEÓN, A. y otros (1983): Museo Arqueológico de Álava: 101-108, Victoria.

BLASCO, $M^{a}$ C. (1987): “Un ejemplar de fíbula "ad occhio" en el Valle del Manzanares", Bol As. Esp. Am. Arqu. 23: 18-28.

(1994): "Origen y desarrollo del Horizonte de Cogotas I en el Alto Tajo", Trabalhos de Antr. e Etn. XXXIV (3-4): 151-165.

_et alii (1984-85): "Depósito votivo en un yacimiento de la Edad del Bronce en el valle del Manzanares (Perales del Río, Getafe, Madrid)", CuPAUAM 11-12, I: 69-83. 
BLASCO et alii (1991): "Enterramientos del horizonte Protocogotas en el valle del Manzanares", CuPAUAM 18: 55-112.

- et alii (1995): "Fecha de C-14 de la Fase Protocogotas I del yacimiento de Perales del Río", CuPAUAM 22: 83-90.

y BARRIO, J. (1986): "Dos nuevos yacimientos prehistóricos en el sector III de Getafe", N.A.H. 27: 72-147.

— y LUCAS, Ma R. (e.p.): "Lectura social de la metalurgia de Madrid y Guadalajara durante la Edad del Bronce", Simposio de Sigüenza (Guadalajara), 2000.

— y ROVIRA, S. (1992/93): "La metalurgia del cobre y del bronce en la región de Madrid", Tabona 8, II: $397-415$.

BRUN, P. (1986): La civilisation des Champs d'urnes. Etude critique dans le Bassin parisien, Paris.

CHERTIER, B. (1976): Les nécropoles de la Civilisation des Champs d'Urnes dans la région des Marais de Saint-God (Marne), "VII Supl. Gallia Préhistoire", Paris.

CONDE, J. F. et alii (1996): "El Cerro del Berrueco (Salamanca), nuevas propuestas para un problema olvidado", Bol. Asoc. Española de Am. de la Arq. 36: 47-71.

CUNLIFFE, B. (1992): "Pits, Preconceptions and propitiation in the British Iron Age", Journal Archaeology 11, 1: 69-83.

DELIBES, G. (1978): “Una inhumación triple de facies Cogotas I en San Román de la Hornija (Valladolid)”. TP 35: 225-250.

(1999/2000): "Una pareja de alfileres de bronce procedentes del yacimientos Cogotas I de" El Tomillar", Santuola/VI, Estudios en homenaje al profesor Dr. García Guinea: 265-270, Santander.

— - y ABARQUERO, J.(1997): "La presencia de Cogotas I en el País Valenciano: Acotaciones al tema desde una perspectiva meseteña", Saguntum 30: 115-134.

— et alii (1990): "Cerámica de la plenitud de Cogotas I: El yacimiento de San Román de la Hornija (Valladolid)”, B.S.A.A., LVI: 105-138, Valladolid.

, RODRÍGUEZ, J.A. y SANTONJA, M. (1991): "Cuatro hallazgos de oro de la Edad del Bronce en la Meseta Norte", TP 48: 203-213.

ELUÉRE, CH. (1982): Les ors prehistoriques. L'Age du bronze en France, Paris.

ESPARZA ARROYO, A. (1990): "Sobre el ritual funerario de Cogotas I", BSAA LVI: 106-143.

FERNÁNDEZ MANZANO, J. (1986): El Bronce Final en la Meseta Norte Española: el utillaje metálico. Junta de Castilla y León.

GASULL, P. (1982): "Los soportes en el Bajo Guadalquivir: intento de clasificación", Mad. Mitt. 23: 62-95.

GONZÁLEZ SALAS, S. (1945): El Castro de Yecla, en Santo Domingo de Silos (Burgos), "Informes y Memorias, 7". Madrid.

GONZÁLEZTABLAS, F.J. y FANO, M.A. (1994): "El fenómeno de la muerte en Cogotas I: una propuesta metodológica", Zephyrus XLVII: 93-103.

HARRISON et alii (1994): Moncín: Un poblado de la Edad del Bronce (Borja, Zaragoza), Zaragoza.

LAGRAND, CH. (1976): "Les civilisations de l'Age du Bronze en Provence", en La Préhistoire Française, T. II: 452-458.

LÓPEZ, P. (Coord.) (1997): El paisaje vegetal de la Comunidad de Madrid durante el Holoceno Final, "Arq. Paleont. y Etnog." 5, Madrid.

MARTÍN DE LA CRUZ, J.C. y PERLINES, M. (1993): "La cerámica a torno de los contextos culturales de finales del II milenio a.C. en Andalucía", I Cong. Arq. Peninsular. T.A.E. 33 (3-4): 335-349. Porto.

MESADO, N. (1999): Los movimientos culturales de la Edad del Bronce y el Mediterráneo como vía de llegada, Valencia. 
MÉNDEZ MADARIAGA, A. (1994): "La Edad del Bronce en Guadalajara: Una visión de conjunto", en La Edad del Bronce en Castilla-La Mancha: 111-144, Toledo.

MUÑOZ, K. y ORTEGA, J. (1997): "Elementos de inspiración orientalizante en la Cuenca media del río Tajo; El yacimiento de "puente Largo de Jarama" (Aranjuez, Madrid)", Spal 6: 141-163.

PELLICER, M. (1984): "Elementos ultrapirenáicos y hallstátticos en el Horizonte del Bronce Final-Hierro del Noreste hispano", Habis 15: 309-343.

(1992-93): "El Bronce Reciente e inicios del Hierro en Andalucía Oriental”, Bajo Aragón, Prehistoria, 9-10: 339-363, Zaragoza.

(1992): "Problemática del Bronce e inicios del Hierro en Iberia", Paleoetnología de la Península Ibérica, Complutum 2-3: 11-18, Madrid.

PEREIRA, J. (1994): "La transición del Bronce Final al Hierro en la Meseta Sur", Actas: La Edad del Bronce en Castilla-La Mancha: 37-85, Toledo.

PÉREZDE BARRADAS, J. (1936): "Nuevos estudios sobre Prehistoria madrileña I. La colección Bento". Anuario de Prehistoria madrileña IV-V-VI. 1933-35: 1-90, Madrid.

PRIEGO, $M^{a}$ C. (1978): "Una obra maestra de la orfebrería prehistórica madrileña: El brazalete de oro de la Torrecilla (Getafe)", Villa de Madrid 59: 17-53.

RODANÉS, J. Ma (1995): "El Bronce Medio y Tardío en La Rioja", CuPAUAM 22: 37-82, Madrid.

ROMERO, F. y RAMÍREZ, Ma L. (1996): "La cultura del Soto. Reflexiones sobre los contactos entre el Duero Medio y las tierras del Sur Peninsular durante la Primera Edad del Hierro" en M.'A.QUEROL y T. CHAPA (eds.), Homenaje al Profesor Manuel Fernández Miranda, Comuplutum extra 6-I: 313-326.

VALIENTE MALLA, J. (1992): "El Cerro del Padrastro de Santamera y la Protohistoria del Valle del Henares", en J. VALIENTE (ed.): La celtización del Tajo Superior: 11-44, Universidad de Alcalá.

WERNER, S. (1987): El Bronce Final y la Primera Edad del Hierro en Centroeuropa, "Cuadernos de Apoyo", 3-5 UAM, Madrid.

WERNER, S. (1987/8): “Consideraciones sobre la cerámica con decoración grafitada en la Península Ibérica”, Kalathos 7-8: 185-194. 

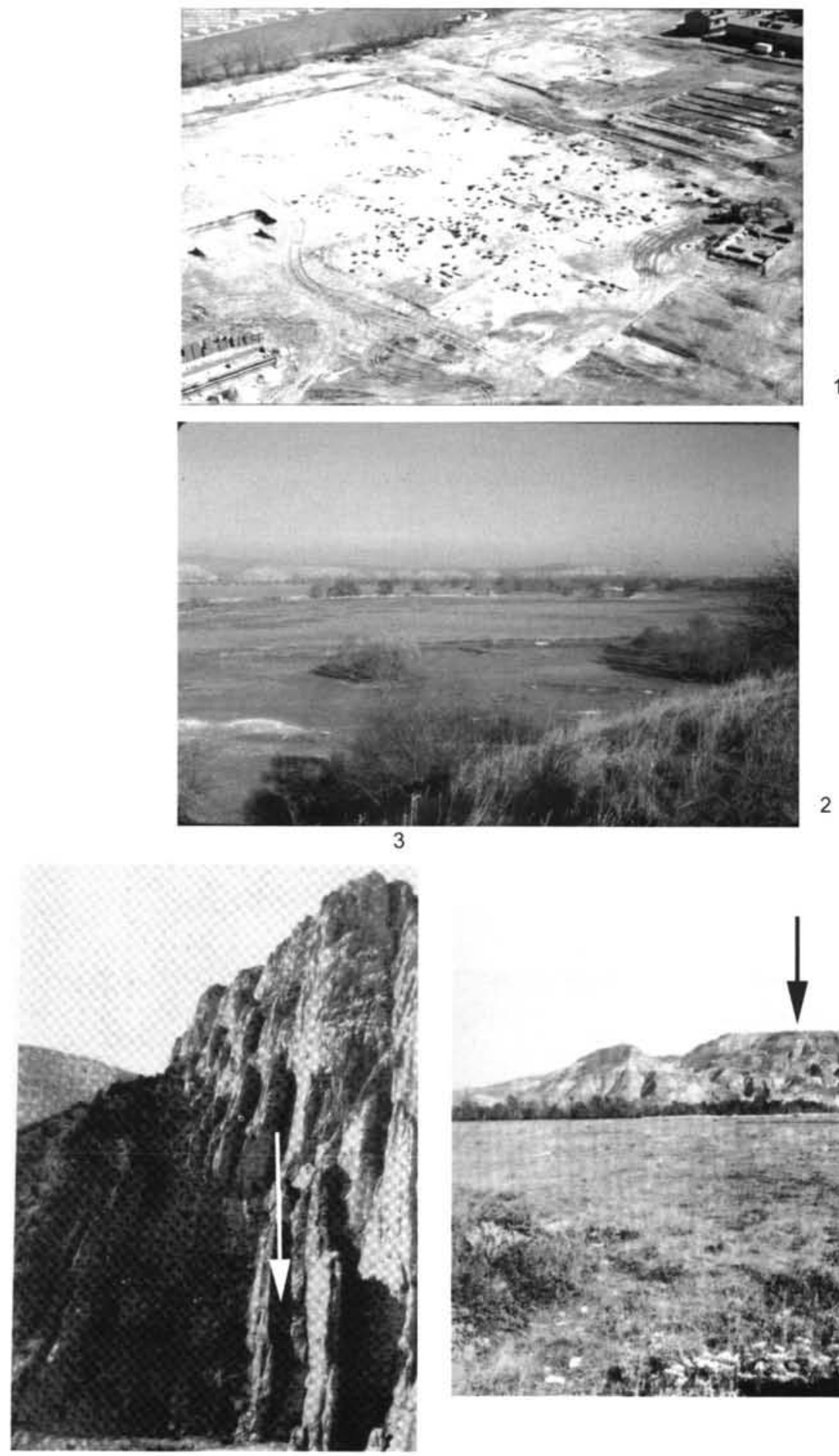

Figura 1: Emplazamientos de los yacimientos de Cogotas I. 1 Caserío de Perales (Bajo, Manzanares, Madrid); 2: La Fábrica de Ladrillos (Bajo, Manzanares, Madrid); 3: Yecla de Silos, Burgos (según González Salas 1945); 4: Cerro del Ecce Homo (Valle del Henares, Alcalá de Henares) (según Almagro y Fernández Galiano 1980). 


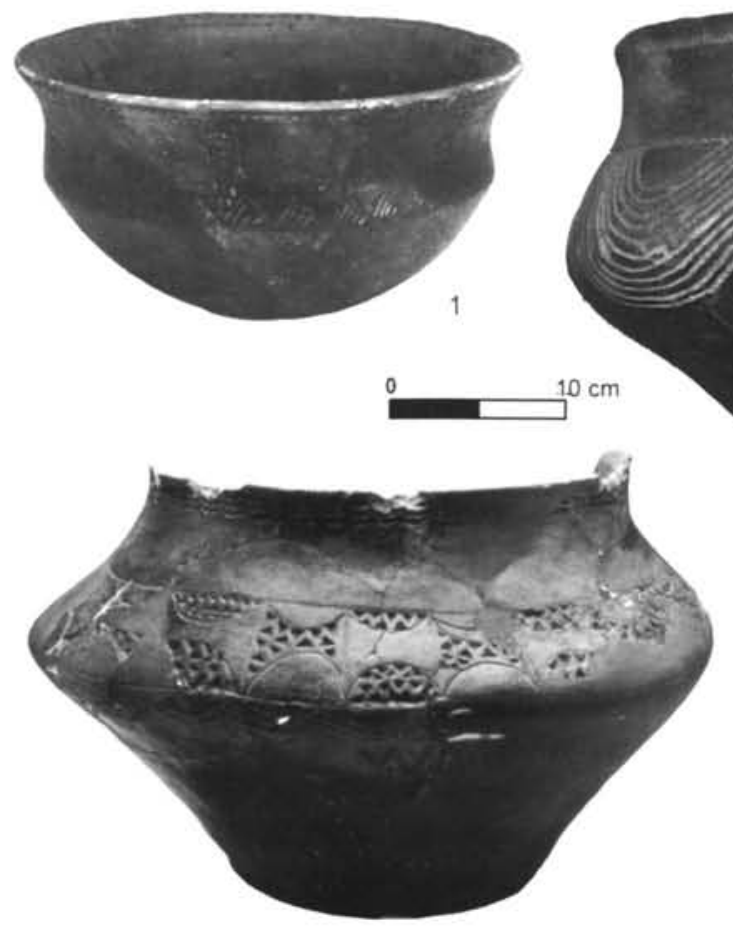

3

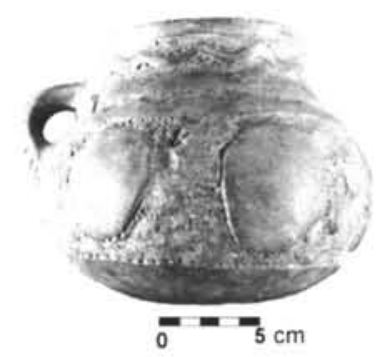

5

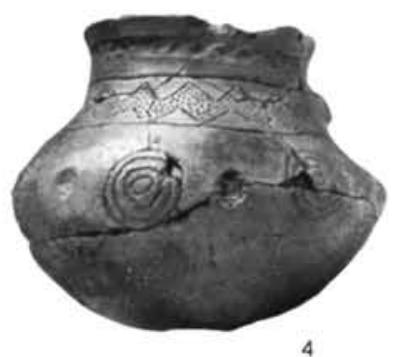

4
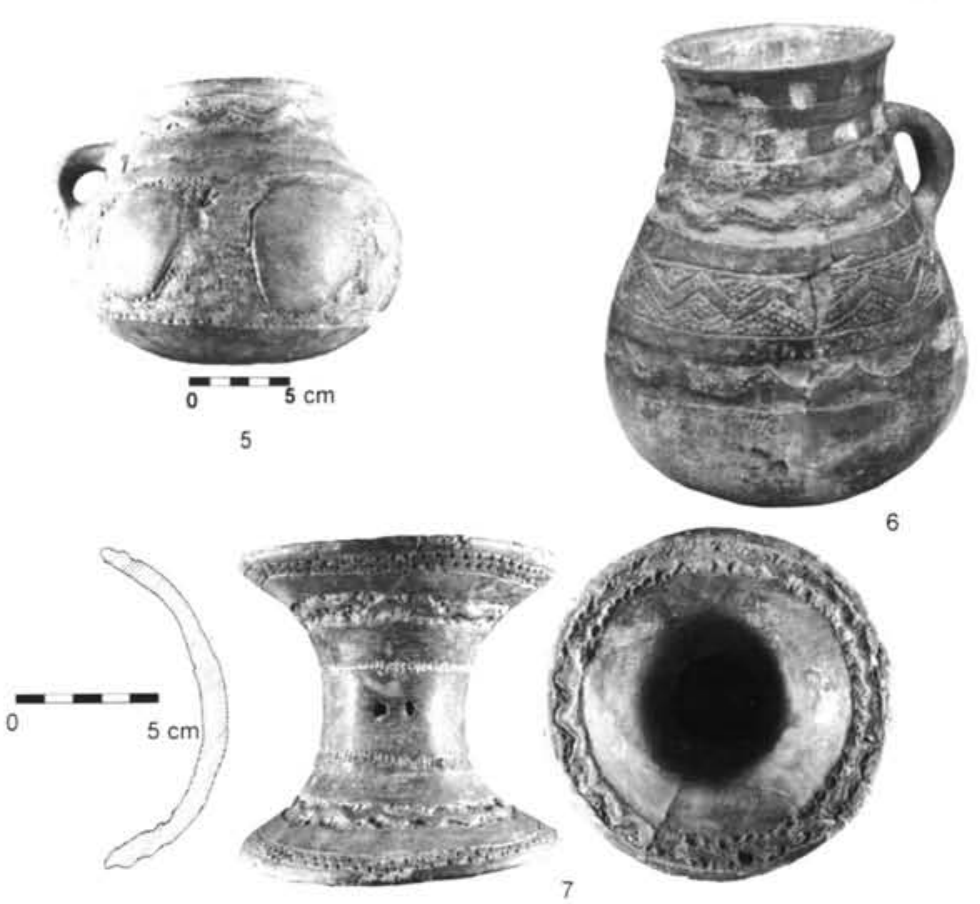

Figura 2: Materiales cerámicos. 1: Protogotas (Arenero de Pedro Jaro II, Museo Municipal de San Isidro de Madrid); 2 a 7: Cogotas I; 2,5 y 7: Arenero de Valdivia (Colec. Bento MARC); 3 y 6: Arenero de Valdivia (Museo Municipal de San Isidro de Madrid); 4: Arenero de La Fábrica de Ladrillos (Museo Municipal de San Isidro de Madrid). 


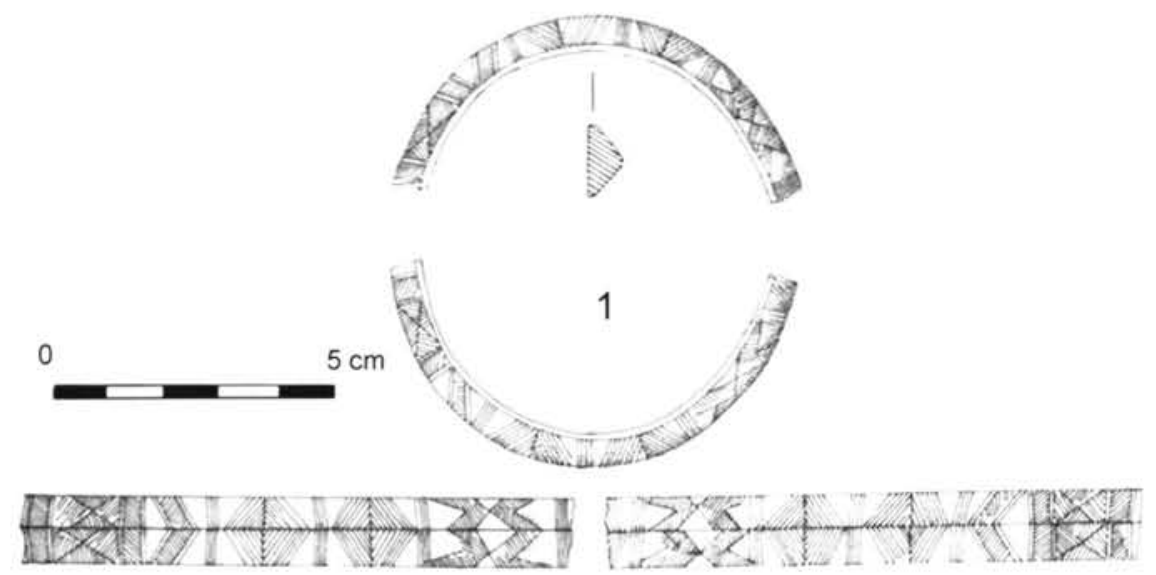

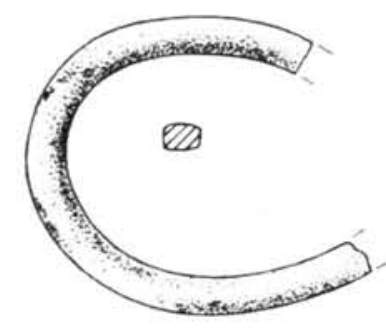

2
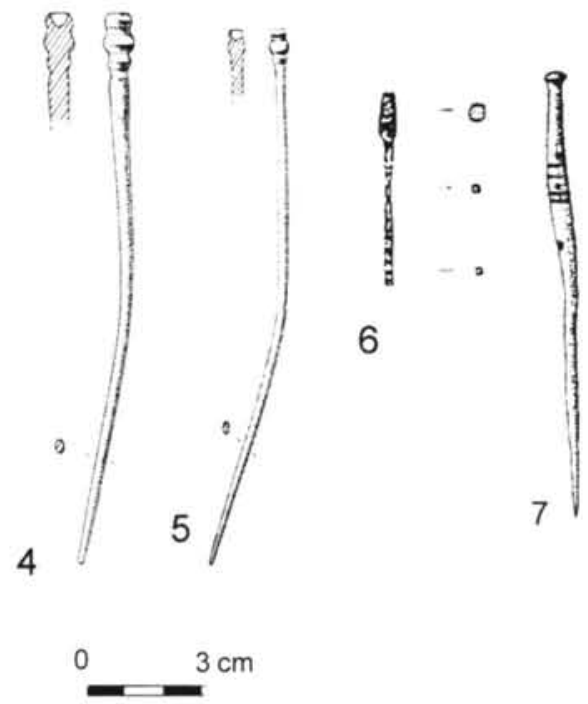

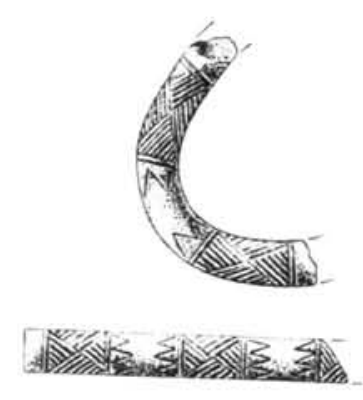

3
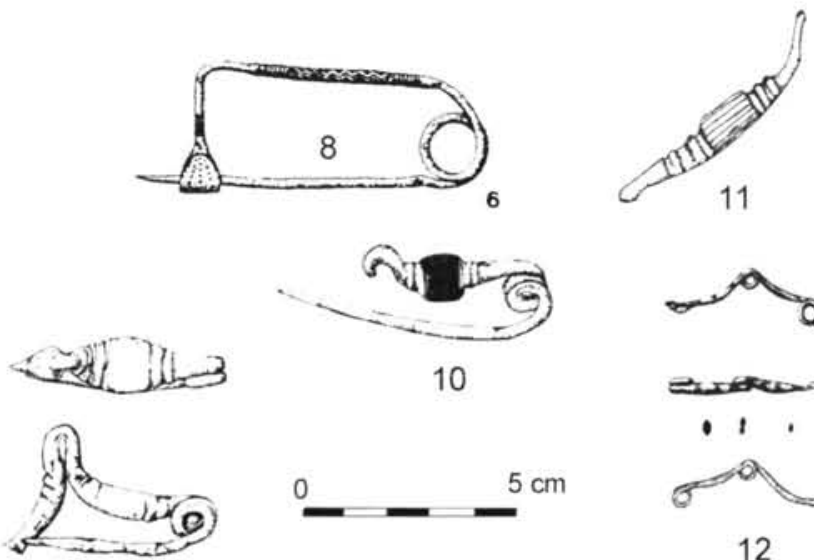

9

Figura 3: Adornos metálicos Cogotas I. 1: Brazalete de Alarilla (Museo de Guadalajara); 2 y 3: El Berrueco, cabaña Be2 (según Fernández Manzano 1986); 4 y 5 Alfileres de El Tomillar (Según Delibes 1999); 6: Alfiler del Caserío de Perales ; 7: Alfiler de El Berrueco (según Conde et alii 1996); 8: Fíbula de arco de violín procedente de El Berrueco (según Conde et alii 1996); 9: Fíbula de codo de San Román de la Hornija (según Delibes 1978); 10: Fragmento de fíbula de codo procedente de Silos (según Fernández Manzano 1986); 11: Fíbula de codo de El Berrueco (según Fernández Manzano 1986);12 Fíbula «ad occhio» de Perales del Río (según Blasco 1987). 